\title{
Demographic and clinical aspects of an Italian patient population with chronic fatigue syndrome
}

\section{Caratteristiche demografiche e cliniche di una popolazione italiana affetta da Sindrome d'affaticamento cronico}

\author{
N. Carlo-Stella, M. Cuccia \\ Dipartimento di Genetica e Microbiologia, Università di Pavia
}

\begin{abstract}
RIASSUNTO
La sindrome d'affaticamento cronico è una diagnosi di esclusione caratterizzata da stanchezza debilitante che non possa essere attribuita ad altre patologie. Dall'eterogeneità della sintomatologia lamentata dai pazienti si può tuttavia delineare una sintomatologia con caratteristiche reumatologiche, infettive e neurologiche. Colpisce con maggior frequenza le donne e tutte le classi sociali, in accordo con la letteratura internazionale. Purtroppo mancano stime precise dell'incidenza e prevalenza della sindrome in Italia. La terapia è pressoché inesistente e si appoggia a rimedi empirici non basati sull'evidenza.
\end{abstract}

Reumatismo, 2009; 61(4):285-289

\section{INTRODUCTION}

C hronic Fatigue Syndrome (CFS) is a debilitating syndrome characterized by fatigue which, by exclusion, cannot be ascribed to another illness. Because of the vagueness of the symptoms and signs in patients with CFS, various attempts have been made to define the syndrome and classification criteria have been developed (13 ), of which the most well-known and used are those of Fukuda et al. (1) This classification includes two major criteria:

1) the presence of new persisting, debilitating fatigue that does not resolve with bed rest, reduces daily activities by at least $50 \%$ and lasts for at least six months;

2) the exclusion of any other known disease which can cause fatigue; and at least eight of eleven minor criteria (low-grade fever, shivers, pharyngitis, cervical or axillary lymphnodes, myal-

Indirizzo per la corrispondenza:

Dr. Nicoletta Carlo-Stella

Via Menocchio, 10

27100 Pavia

E-mail:nickics@libero.it gias, arthralgias without arthritis, headache, unrefreshing sleep, general and prolonged fatigue after physical exercise that does not resolve within 24 hours after rest, and neuropsychological/cognitive impairment).

The causes of the syndrome are unknown, but three hypotheses are considered important. The first concerns the involvement of a bacterial or viral pathogen and indeed CFS at its onset was termed chronic mononucleosis. However the four-city surveillance study by the CDC (Atlanta, USA) excluded most pathogens as the sole causative agent for CFS. This hypothesis could still be valid if the pathogen were to be the precipitating event in an immunogenetically vulnerable host. The second hypothesis involves immune system activity. In fact, the only laboratory finding that is altered in CFS is a deficit in NK cell lytic activity (4) and recently we have found evidence of genetic susceptibility to an imbalance in cytokine production (5) in patients with CFS.

The third possibility is an involvement of the hypothalamic pituitary adrenal axis due to a genetic susceptibility (6) and having stress as a precipitating factor. An increased production in cortisol would cause a depression in the immune system's 
function and make the host more vulnerable to an infection.

The aim of this study was to gather the demographic and clinical characteristics of a group of Italian patients with certified Chronic Fatigue Syndrome (CFS) through an observational study and compare these data with the updated, available international literature on the subject. Secondary objectives were to collect information on laboratory and image testing in order to exclude an alternative diagnosis and to try to outline a pattern of symptoms that can better define the syndrome with the etiological hypotheses in mind.

\section{PATIENTS AND METHODS}

Patients were recruited through the Italian referral centers for CFS (Centro di Riferimento Oncologico of Aviano, Prof. U. Tirelli, and the Dept. of Infectious Diseases, University of Chieti, Prof. G. Pizzigallo).

Patients who also had a diagnosis of fibromyalgia, irritable bowel syndrome or other non-invalidating chronic pathologies (allergies or hypertension) were not excluded from the study.

A questionnaire was developed to investigate the demographic and clinical characteristics of the participants, including age, sex, education and profession, timing and nature of the onset of symptoms, persistence of symptoms (fatigue, pain, weakness, cognitive impairment, fever, arthralgia/myalgias, depression), duration of illness, and criteria used to diagnose CFS. Room was left for patients to write other symptoms. Laboratory and image testing were also investigated, as were viral serology, personal and family histories for autoimmune/allergic diseases, CFS, genetic diseases, and prescribed therapy.

One-hundred and nineteen patients were contacted by phone to participate in the study. To the 81 patients who agreed the questionnaire was sent home. The study was part of the development of a blood bank at the University of Pavia (laboratory of Immunogenetics, Department of Genetics and Microbiology, Prof. M. Cuccia) and the patients arrived on the day of blood withdrawal with the questionnaire completed. Any omittance was completed with documentation provided by the patients and controlled by the author.

Informed written consent was obtained from all of the participants; this study was approved by the ethics committee of the University of Pavia.

\section{RESULTS}

\section{Demographic aspects}

81 patients completed the questionnaire and returned it. The demographic characteristics are summarized in Table I. We observed a bias towards female sex (3:1 ratio) in agreement with international literature (7-11). Patients' occupation is evenly distributed and dominated by employees and housewives, whereas teachers and healthcare professionals come in third position.

\section{Clinical characteristics}

Patients age is mostly comprised between 18 and 50 years, and many patients have been suffering from CFS from a long period of time (mean 8.9 years) (Table I). We can infer that the patient population is in the chronic state of the disease with relapses and periods of well-being.

The onset of symptoms is freely described by patients in the questionnaire. We observed that the infectious (Herpes viruses), neurological (CRHACTH-cortisol axis) and immune hypotheses of the syndrome are well reflected by the descriptions of the onset of CFS (Table II). In fact, the flu-like

Table I - Demographic data.

\begin{tabular}{|ll|}
\hline Sex & \\
M & $20 / 81(25 \%)$ \\
F & $61 / 81(75 \%)$ \\
\hline Age at onset (years) & \\
Mean; range & $44.7(11-68)$ \\
\hline Disease duration (years) & \\
Mean; range & $8.9(1-33)$ \\
\hline Onset & \\
Acute & $34 / 80(43 \%)$ \\
Subacute & $4 / 80(8 \%)$ \\
Chronic & $39 / 80(49 \%)$ \\
\hline Education & \\
Junior high school & $28 / 81(34.6 \%)$ \\
Senior high school & $30 / 81(37 \%)$ \\
College degree & $13 / 81(16 \%)$ \\
Unspecified & $10 / 81(12.4 \%)$ \\
\hline Profession & \\
Entrepreneur & $2 / 81(2.5 \%)$ \\
Employee & $19 / 81(23.4 \%)$ \\
Teacher & $6 / 81(7.4 \%)$ \\
Nurse & $6 / 81(7.4 \%)$ \\
Artisan & $10 / 81(12.3 \%)$ \\
Factory worker & $1 / 81(1.2 \%)$ \\
Housewife & $19 / 81(23.4 \%)$ \\
Student & $4 / 81(4.9 \%)$ \\
Retired & $9 / 81(11.1 \%)$ \\
Unspecified & $5 / 81(6.2 \%)$ \\
\hline
\end{tabular}


syndrome described by patients, including both fever and pharyngitis, is present in $32.1 \%$ of patients. An onset with neurological symptoms (including amnesias, cognitive impairment, difficulty concentrating, confusion, headaches, vertigo) is present in $42 \%$ of cases. Fatigue/weakness are constantly present in $63 \%$ of patients. Swollen lymphnodes were described by $8.6 \%$ of patients, and dyspnea occurred in $2.5 \%$ patients It was a surprise to observe the presence of arthralgia sine artrhitis and/or myalgias as part of the onset of CFS $(49.4 \%)$, which would confirm the validity of the Canadian criteria that are gaining consensus in the debate on CFS. However at the time being the criteria most widely used in Italy by the referral centers for CFS are those developed by Fukuda et al. (1) $(100 \%$ cases).

Persisting symptoms (Table III) constantly include fatigue (92.6\%), post-exertional malaise $(91.4 \%)$ and pain $(87.6 \%)$. These are general symptoms that are often encountered in systemic diseases. However, patients also describe arthralgia/myalgia (89\%), neurological symptoms (especially lack of concentration in $86.4 \%$ of patients), and low-grade fever $(63 \%)$, as persisting symptoms. These observations are helpful in order to better outline the characteristics of the syndrome, although none are pathognomonic.

The accompanying symptoms present in these patients underline the heterogeneity of CFS. We observed a predominance of neurological and psychiatric symptoms (including unrefreshing sleep $(16 \%)$, anxiety $(3.7 \%)$, transitory paresis $(3.7 \%)$, the afore-mentioned cognitive symptoms $(26 \%)$, and headaches (13.6\%), irritable bowel syndrome (9.9\%), arthralgia/myalgias (11.1\%), swollen lymphnodes $(11 \%)$, and dyspnea $(7.4 \%)$.

The validity of the Fukuda criteria is underscored by laboratory and image tests. These patients have undergone a wide variety of tests that result in the normalcy ( $73 \%$ of patients) of most parameters studied.

The alterations noted (herniated disks in $12.3 \%$ of patients, 1 patient with Milwaukee shoulder, 2 with carpal tunnel syndrome, 1 patient with a reactive lymphnode) are frequent in the general population and unlikely to influence a diagnosis of CFS. The viral serology studied in many patients shows evidence of exposure to EBV (45.7\%), a characteristic that has already been described (Holmes et al. International literature generally confirms these data and also includes exposure to CMV (9.9\% in our study), HHV6 (6.2\% in our patients), En-
Table II - Clinical characteristics at onset of CFS in 81 Italian patients.

\begin{tabular}{|lll|}
\hline \multicolumn{2}{|l|}{ Initial symptoms } \\
\hline Fatigue/weakness & $51 / 81$ & $\mathbf{6 3} \%$ \\
\hline Fever & $21 / 81$ & $26 \%$ \\
\hline Pharyngitis & $8 / 81$ & $9,9 \%$ \\
\hline Influenza-like & $26 / 81$ & $32,1 \%$ \\
\hline Arthromyalgias & $40 / 81$ & $\mathbf{4 9 , 4} \%$ \\
\hline Neurological problems & $34 / 81$ & $\mathbf{4 2} \%$ \\
\hline Sleep disturbances & $13 / 81$ & $16 \%$ \\
\hline Enlarged lymphnodes & $7 / 81$ & $8,6 \%$ \\
\hline Dyspnea & $2 / 81$ & $2,5 \%$ \\
\hline
\end{tabular}

Table III - Persisting symptoms of CFS in 81 Italian patients.

\begin{tabular}{|c|c|c|}
\hline Persisting symptoms & & \\
\hline Tiredness & $75 / 81$ & $92,6 \%$ \\
\hline Fatigue & $74 / 81$ & $91,4 \%$ \\
\hline Pain & $71 / 81$ & $87,6 \%$ \\
\hline Concentration difficulties & $70 / 81$ & $86,4 \%$ \\
\hline Arthromyalgias & $72 / 81$ & $89 \%$ \\
\hline Fever & $51 / 81$ & $63 \%$ \\
\hline Depression & $34 / 81$ & $42 \%$ \\
\hline
\end{tabular}

Table IV - Therapy.

\begin{tabular}{|ll|}
\hline Ampligen & $1 / 81(1.2 \%)$ \\
\hline Antibiotics & $10 / 81(12.3 \%)$ \\
\hline Antidepressants & $25 / 81(30.9 \%)$ \\
\hline Antiviral/IFN & $7 / 81(8.6 \%)$ \\
\hline Cytokines & $1 / 81(1.2 \%)$ \\
\hline Steroids & $31 / 81(38.3 \%)$ \\
\hline Magnesium & $12 / 81(14.8 \%)$ \\
\hline NSAIDs & $11 / 81(13.6 \%)$ \\
\hline Physiotherapy & $3 / 81(3.7 \%)$ \\
\hline Vitamin supplements & $41 / 81(50.6 \%)$ \\
\hline
\end{tabular}

teroviruses (3.7\%) and parvovirus B19 as possible causative agents $(13,14)$.

If this study has begun to delineate some observations on the clinical characteristics of patients with CFS, the same cannot be said for therapy prescribed to patients, which is heterogeneous and of little benefit (Table IV). There is little compliance towards physiotherapy and cognitive-behavioral therapy (CBT) proposed by international literature (17). It has mostly encountered patients' resistence when proposed, but systematic studies are lacking in Italy.

Patients' history has shown that CFS does not seem to be inheritable in a Mendelian manner (CFS is ab- 
sent in $95.1 \%$ of patients' families, and present in $2.5 \%$; undetermined: $2.5 \%$ ). We did not have monzigotic or dizogotic twins among the patient cohort, nor does the syndrome seem to be transmitted in families. However, we observed many allergies or autoimmune diseases both in the patient (38.3\% and $13.5 \%$ respectively) or in their family (22.2\% and $28.4 \%$ respectively). These data compelled us to pursue the study of certain genes in the immune system as being possibly involved in CFS.

\section{DISCUSSION}

The epidemiology of CFS has been studied in the United States where the estimated prevalence was found to be $0.42 \%$ (7), Asia (9), Australia (8) and some European countries $(11,12,16)$ (Fig. 1). Most countries where the epidemiology has been studied have an approximately similar estimate with the exception of Sweden (2.36\%) and Australia $(0.037 \%)$. The literature is discordant on the subject of social class: some studies have indicated an increased presence of teachers and healthcare professionals (11) but we have found evidence of an equal distribution among the working classes in accordance with more recent literature (12), and all social classes seem to be affected.

In Italy, estimates of the prevalence and incidence of the syndrome are unavailable.

Two studies have been published in Italy concerning the epidemiology of CFS. The first, published in 1994 (10), studied the prevalence of CFS in patients with fatigue who were sent to a secondary referral center in Internal Medicine (127 patients). Of these, $30 \%$ did not fulfill the second major criteri- um (another disease was identified as cause of fatigue) or did not fulfill all of the inclusion criteria. $28.5 \%$ remained without a definitive diagnosis, $59 \%$ had another diagnosis (of a psychiatric nature), and $9.5 \%$ of the patients that completed the study $(6 / 63)$ were diagnosed with Chronic Fatigue Syndrome. The second study, published in 1999 (15) compared the two existing case definitions of CFS: (Holmes and Fukuda) patients with persistent fatigue were screened with a questionnaire, lab testing and a psychiatric interview. The authors concluded that patients fulfilling the Fukuda criteria were more likely to be male, of upper social class, married, and less likely to have had an acute onset (with symptoms and signs of a flu-like disease) with respect to the patients fulfilling the Holmes criteria.

This study has outlined a syndrome which can be considered a disease entity characterized by fatigue, infectious, neurological and rheumatological symptoms. These characteristics are present at the onset of the illness and tend to persist over time. Thus a dysregulation of psychosomatic nature cannot be ruled out as the primum movens of CFS. In fact a Japanese study on the SNPs of the promoter of the serotonin receptor gene supports this hypothesis (6).

The Italian patient population studied has demographic aspects in accordance with international literature. Precise epidemiological data are lacking in Italy, as are studies on the effectiveness of therapy prescribed by the referral centers for CFS.

\section{ACKNOWLEDGEMENTS}

The authors wish to thank the Associazione Malati di CFS Onlus and Dr. Lorenzo Lorusso for their enthusiasm and help during this study.

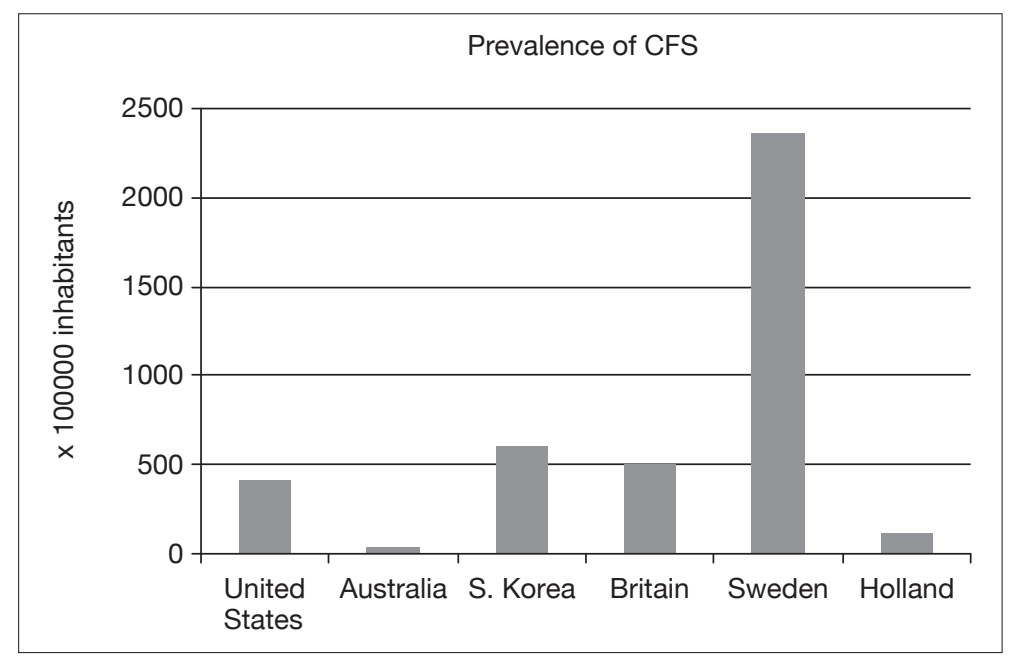

Figure 1 - Prevalence of CFS in populations around the world. 


\section{SUMMARY}

Objective: The purpose of this study was to investigate demographic and clinical aspects of a group of Italian patients with Chronic Fatigue Syndrome (CFS) which have not yet been described, in order to compare them with international literature, and to better define certain clinical aspects of the syndrome with respect to the Fukuda et al. case definition.

Methods: A detailed questionnaire was sent to patients with certified CFS diagnosed in a referral center and the data were collected two weeks later.

Results and conclusions: Besides persistent fatigue, a clinical syndrome with infectious, neurological and rheumatological characteristics is outlined from the data. Demographic characteristics of Italian patients are very similar to those described in international literature. Therapy has yet to be validated with evidence-based studies in Italy. Studies on the prevalence of CFS in Italy are lacking and would be useful to better define the syndrome in this Mediterranean population.

Parole chiave - Sindrome d' affaticamento cronico, Italia, definizione clinica, demografia, malattie infettive. Key words - Chronic Fatigue Syndrome, Italy, case definition, demography, infectious diseases.

\section{REFERENCES}

1. Fukuda K, Straus SE, Hickie I, Sharpe MC, Dobbins JG, Komaroff A. The chronic fatigue syndrome: a comprehensive approach to its definition and study. International Chronic Fatigue Syndrome Study Group. Ann Intern Med 1994; 121: 953-9.

2. Reeves WC, Lloyd A, Vernon SD, Klimas N, Jason $\mathrm{LA}$, Bleijenberg $\mathrm{G}$ et al. Identification of ambiguities in the 1994 chronic fatigue syndrome research case definition and recommendations for resolution. BMC Health Serv Res 2003; 3: 25.

3. Carruthers BM, Jain AK, DeMeirleir K, Peterson DL, Klimas NG, Lerner AM et al. Myalgic encephalomyelitis/chronic fatigue syndrome: Clinical working case definition, diagnostic and treatment protocols. J Chronic Fatigue Syndr 2003; 11: 7-115.

4. Klimas NG, Salvato FR, Morgan R, Fletcher MA. Immunologic abnormalities in chronic fatigue syndrome. J Clin Microbiol 1990; 28: 1403-10.

5. Carlo-Stella N, Badulli C, De Silvestri A, Bazzichi L, Martinetti M, Lorusso L, et al. A first study of cytokine genomic polymorphisms in CFS: Positive association of TNF-857 and IFNgamma 874 rare alleles. Clin Exp Rheumatol 2006; 24: 179-82.

6. Narita M, Nishigami N, Narita N, Yamaguti K, Okado $\mathrm{N}$, Watanabe $\mathrm{Y}$ et al. Association between serotonin transporter gene polymorphism and chronic fatigue syndrome. Biochem Biophys Res Comm 2003; 311: 264-66.

7. Jason LA, Richman JA, Rademaker AW, Jordan KM, Plioplys AV, Taylor RR, et al. A community-based study of chronic fatigue syndrome. Arch Intern Med 1999; 159: 2129-37.

8. Lloyd AR, Hickie I, Boughton CR, Spencer O, Wakefield D. Prevalence of chronic fatigue syndrome in an Australian population. Med J Aust 1990; 153: 522-8.
9. Kim CH, Shin HC, Won CW. Prevalence of chronic fatigue and chronic fatigue syndrome in Korea: community-based primary care study. J Korean Med Sci 2005; 20: 529-34.

10. Conti F, Priori R, De Petrillo G, Rusconi AC, Arpino $\mathrm{C}$, Valesini G. Prevalence of chronic fatigue syndrome in Italian patients with persistent fatigue. Ann Ital Med Int 1994; 9: 219-22.

11. Wessely S, Chalder T, Hirsch S, Wallace P, Wright D. The prevalence and morbidity of chronic fatigue and chronic fatigue syndrome: a prospective primary care study. Am J Public Health 1997; 87: 1449-55.

12. Bazelmans E, Vercoulen JH, Galama JM, van Weel C, van der Meer JW, Bleijenberg G. [Prevalence of chronic fatigue syndrome and primary fibromyalgia syndrome in The Netherlands] Ned Tijdschr Geneeskd 1997; 141: 1520-3.

13. Sairenji T, Yamanishi K, Tachibana Y, Bertoni G, Kurata T. Antibody responses to Epstein-Barr virus, human herpesvirus 6 and human herpesvirus 7 in patients with chronic fatigue syndrome. Intervirology 1995; 38 : 269-73.

14. Kerr JR. Pathogenesis of Parvovirus B19 infection: host gene variability, and possible means and effects of virus persistence. J Vet Med B 2005; 52: 335-9.

15. Arpino C, Carrieri MP, Valesini G, Pizzigallo E, Rovere $\mathrm{P}$, Tirelli $\mathrm{U}$. Idiopathic chronic fatigue and chronic fatigue sindrome: a comparison of two case-definitions. Ann Ist Sup San 1999; 35: 435-41.

16. Evengard B, Jacks A, Pederson NL, Sullivan PF. The epidemiology of chronic fatigue in the Swedish Twin Registry. Psychol Med 2005; 35: 1317-26.

17. Whiting P, Bagnall AM, Sowden AJ, Cornell JE, Mulrow $\mathrm{CD}$, Ramirez $\mathrm{G}$. Interventions for the treatment and management of chronic fatigue syndrome: A systematic review. JAMA 2001; 286: 1360-8. 